The varied results in the literature make it possible to select studies that show an independent association between hypertriglyceridaemia and coronary heart disease, like the three that Peter $\mathrm{H}$ Winocour cites. ${ }^{2}$ But many studies support the opposite conclusion. ${ }^{5-7}$ Triglycerides may have a role in risk prediction when well standardised measurements of high density lipoprotein cholesterol are not available, as Winocour suggests. The negative correlation between the two measurements means that the triglyceride concentration can serve as a surrogate for the high density lipoprotein cholesterol concentration, albeit a relatively imprecise one. For any lipoprotein test, and especially for triglycerides, its accuracy in predicting risk depends on the quality of the measurement in the specific laboratory, so clinicians should learn about the accuracy of lipid tests available in the laboratory they use.

Whether to measure triglycerides is a moot issue once hypercholesterolaemia is found and a decision made to measure low density lipoprotein cholesterol. Many laboratories use an indirect measurement of low density lipoprotein cholesterol which requires knowledge of the triglyceride concentration. Consistent evidence that triglycerides have an important independent role in preventing coronary heart disease, however, remains elusive; calls for triglyceride testing must appeal to faith rather than established fact.

Stanford University,

Palo Alto, CA 94304, USA

Associate professor,

ANDREW L AVINS

University of California, San Francisco,

74 New Montgomery Street,

San Francisco, CA 94105, USA

1 Cruickshank AM. Triglyceride concentration and coronary heart disease. $B M F$ 1994;309:668. (10 September.)

2 Winocour PH. Triglyceride concentration and coronary heart disease. $B M 7$ 1994;309:668. (10 September.)

3 Lipid Research Clinics Program. The Lipid Research Clinics coronary primary prevention trial results. II. The relationship of reduction in incidence of coronary heart disease of cholesterol lowering. IAMA 1984;251:365-74.

4 Grady D, Rubin SM, Pettiti DB, Fox CS, Black D, Ettinger B, et al. Hormone therapy to prevent disease and prolong life in et al. Hormone therapy to prevent disease and prolong life in
postmenopausal women. Ann Intern Med 1992;117:1016-37.

postmenopausal women. Ann Intern Med 1992;117:1016-37.
5 Avins AL, Haber RJ, Hulley SB. The status of hypertri-

Avins AL, Haber RJ, Hulley SB. The status of hypertri-
glyceridemia as a risk factor for coronary heart disease. Clin Lab Med 1989;9:153-68.

6 Pocock SJ, Shaper AG, Phillips AN. Concentrations of high density lipoprotein cholesterol, triglycerides, and total cholesterol in ischaemic heart disease. $B M \mathcal{F}$ 1989;298:998-1002.

7 Criqui M, Heiss G, Cohn R, Cowan LD, Suchindran CM, Bangdivala $\mathrm{S}$, et al. Plasma triglyceride level and mortalit from coronary heart disease. $N$ Engl f Med 1993;328:1220-5.

\section{Child and adolescent mental health services}

EDrToR,-I wish to correct an error that Michel Vanstraelen and I made in our article on purchasers' knowledge of, and plans for, child and adolescent mental health services. ${ }^{1}$ When we first contacted Camden and Islington Health Authority in April 1993 it was able to provide little information about child and adolescent mental health services. I have since been informed by the medical director and director of contracting, however, that later in the year the health authority spent considerable time thinking about its purchasing plans for child and adolescent psychiatry. Our statement that the information in our article was correct as of December 1993 was therefore incorrect.

I am aware of the richness of services available within the area served by Camden and Islington Health Authority and am pleased that the health authority has started to address the purchasing of child mental health services. However, the authority has been able to provide me with only a description of services written by the provider and some general quality standards for child and adult mental health, which have little relevance for child mental health services. This is similar to the level of information provided by other health authorities in our survey.

Substantial numbers of children have psychiatric disorders and need services. A recent report sponsored by the Department of Health shows that provision of services across Britain is patchy and often inadequate. ${ }^{2}$ Purchasers must start to pay more attention to this small but important area of the health service.

DAVID COTTRELI

Professor of child and adolescent psychiatry

Divison of Psychiatry and Behavioural Sciences,

School of Medicine,

University of Leeds,

Leeds LS2 9NN

1 Vanstraelen M, Cottrell D. Child and adolescent mental health services: purchasers' knowledge and plans. BMF 1994;309: 259-61. (23 July.)

2 Kurtz Z, Thornes R, Wolkind S. Services for the mental health of children and young people in England. A national review. London: Department of Public Health, South Thames RHA 1994.

\section{Hepatitis $C$ in asymptomatic blood donors}

\section{Did ethics committee approve study?}

EDIToR,-In their short paper on hepatitis $C$ in asymptomatic British blood donors D J Mutimer and colleagues do not say whether their study was approved by an ethics committee.' In the paper's comment they state that their patients would not have undergone biopsy outside the context of the study.

This point may have been omitted because of lack of space. I would like to be reassured, however, that the project had approval from a research ethics committee. If this was not the case the paper should not have been accepted for publication.

C B SUMMERTON North Manchester Health Authority,

Manchester M8 6RB

1 Mutimer DJ, Harrison RF, O'Donnell KB, Shaw J, Marti $\mathrm{BAB}, \mathrm{Atrah} \mathrm{H}$, et al. Hepatitis $\mathrm{C}$ in asymptomatic British bloo donors with indeterminate seropositivity. BMF 1994;309:847 8. (1 October.)

\section{Authors' reply}

EDITOR,-Screening of British blood donors for antibodies to hepatitis $C$ virus started in September 1991. Donors who are positive for the antibody (with positive or indeterminate results in the confirmatory assay) are excluded from further donation and advised that use of their blood may be unsafe. Guidelines on counselling and investigating these donors do not exist. Experience in areas of high prevalence suggested that donors with indeterminate results are frequently viraemic and may have clinically important liver disease. Results of liver biochemical tests are frequently normal in patients with liver disease related to hepatitis $C$ virus.

All patients who are positive for antibody to the virus (including asymptomatic blood donors) who are referred to Birmingham Liver Unit have been managed according to a protocol. In line with this protocol, liver biopsy has been recommended for all patients. Blood donors were advised that the clinical importance of their seropositivity was unknown and that liver biopsy could exclude important liver disease. Informed consent was obtained from all patients before biopsy. The management protocol was not submitted for approval by the ethics committee.

During the first 12 months of screening more than 100 donors who were positive for the antibody were referred for counselling and investigation. The results of investigation according to this protocol were analysed for each group of patients, including those with indeterminate seropositivity; these were the patients reported on in our paper. Because of the results of this audit we have modified our clinical practice. When results of liver biochemical tests are normal we now reassure donors with indeterminate seropositivity that they do not have important liver disease and that liver biopsy is not required.

Management according to the protocol and audit have also permitted appropriate (and locally relevant) recommendations to be made for managing donors in whom confirmatory assays give positive results. ${ }^{1}$ We have also established protocols that determine which patients should be given antiviral treatment.

We recommend management that follows a protocol, audit, and modification of the protocol according to results. This is particularly important in the management of conditions for which guidelines have yet to be established.

D J MUTIMER Consultant physician E ELIAS

Liver and Hepatobiliary Unit, Consultant physician

Queen Elizabeth Hospital,

Queen Elizabeth Medical Centre,

Birmingham B15 2TH

1 Mutimer DJ, Harrison RF, O'Donnell K, Shaw J, Martin BAB, Atrah $\mathrm{H}$, et al. Hepatitis $\mathrm{C}$ virus infection in the asymptomatic British blood donor. Fournal of Viral Hepatitis (in press).

\section{Intrahepatic cholestasis of pregnancy}

EDITOR,-As in many liver diseases, in intrahepatic cholestasis of pregnancy' appropriate monitoring and treatment are often not instituted because the problem is not recognised and accurate diagnosis not reached. In addition, we know of cases in which warning signs, such as raised results of liver function tests, have been ignored.

It has been suggested that half of unexplained stillbirths in Britain may be caused by intrahepatic cholestasis of pregnancy. Once the condition has been diagnosed the combination of monitoring and early delivery seems to be effective in ensuring a good outcome for mother and baby. Babies' lives can be saved-without the huge costs associated with some procedures-simply by obstetricians and all those caring for pregnant women, including general practitioners, being aware that severe generalised itching is a classic symptom of the disease. We know of women who have been advised to apply camomile lotion for itching so severe that their only relief is to plunge their feet and legs into buckets of ice. Such symptoms should sound warning bells for physicians or obstetricians. Simple measures can be taken to avoid the agony of a needless stillbirth.

Given the likelihood that better education of those caring for pregnant mothers could save lives, we are anxious to ensure that this happens. As a relatively new charity, the British Liver Trust does not have sufficient resources to initiate a campaign to educate medical practitioners. Surely, though, this is precisely the sort of sensible improvement in health care-with identifiable results--that the government is keen to promote.

PETER SCHEUER Chairman, medical advisory committee JENNY CHAMBERS Chair, obstetric cholestasis support group ALISON ROGERS

British Liver Trust

Ipswich IP3 9QG

1 Fagan EA. Intrahepatic cholestasis of pregnancy. BMf 1994; 309:1243-4. (12 November.) 